\title{
Spanish Heritage in Mathematics and Mathematics Education
}

\author{
L. Rico
}

On the occasion of the 12th ICME, the Spanish Committee of Mathematics Education decided to prepare a national presentation entitled Spanish Cultural Heritage.

The presentation takes the form of a series of posters, each of which has a special focus, showing relevant historical events identified according to time and institutions. As a whole, the posters outline a comprehensive historical trajectory devoted to the Hispanic Heritage.

The relevance of mathematics in the relations between Spain and America has remained unbroken since its beginning 520 years ago. Julio Rey Pastor emphasizes the importance and scope of this heritage for its scientific and technological use and its benefits since the discovery of America. Since then, throughout 520 years of continuous cultural cooperation, the mathematical background shared by Spain and the American Republics, people and countries, that have remained solid and permanent.

To present the Spanish Heritage in the ICME 12 of Seoul (Korea), from the Education Commission of the CEMAT (Spanish Mathematics Committee) have been prepared 27 posters, which set out key moments, characters and events in the history of mathematics.

The list of themes chosen is as follows:

1. Spanish Heritage in Mathematics and Mathematics Education.

2. Mathematics and Science in the Discovery of America.

3. The Founding of the First American Universities.

4. First Mathematical-Scientific Publication in the New World.

5. The House of Trade: Navigation, Cartography, and Astronomy.

6. The 16th-Century Mathematics Academy: Philip II, Siliceo, Juan de Herrera.

7. Science and Technology in the 16th Century.

\footnotetext{
L. Rico $(\bowtie)$

University of Granada, Granada, Spain

e-mail: 1rico@ugr.es

(C) The Author(s) 2015 
8. Mathematics in the Baroque Period in Spain.

9. Scientific Policy of the First Bourbons. The Jesuits and Mathematics.

10. Enlightenment Mathematics. The Reforms of Charles III.

11. José Celestino Mutis. An Enlightened Scientist in the New World.

12. Jorge Juan and Antonio de Ulloa. Meridian measurement in Quito.

13. Educational Reforms in Hispano-America, based on the 1812 Constitution.

14. The Compendium of Pure and Mixed Mathematics by D. José Mariano Vallejo.

15. 19th-Century Mathematics.

16. The Metric System in Textbooks in the Second Half of the 19th Century.

17. The Mathematicians of Scientific '98.

18. Andrés Manjón and the Ave María Schools at the end of the 19th Century.

19. The Spanish Republican Exile: the Mathematicians in America.

20. Researching Together: Return Journeys.

21. The Iberoamerican Mathematical Olympiad.

22. Research Centers.

23. Journals, research and collaboration in Mathematics Education.

24. ICME 8 Seville (Spain), July 1996.

25. Miguel de Guzmán (1936-2004) Academic, scientific, and educational legacy.

26. Mathematical Research in Ibero-America, Spain and Portugal.

27. Spanish Mathematics: the last 20 years.

The posters has been prepared by:

- M. de León and A. Timón, from the Institute of Mathematical Research (ICMAT).

- J. Peralta, from University Autonomous of Madrid.

- A. Maz; N. Adamuz; N. Jiménez-Fanjul; M. Torralbo and A. Carrillo de Albornoz, from the University of Cordoba.

- L. Rico; E. Castro-Rodríguez; J. A. Fernández-Plaza; M. Molina; M.C. Cañadas; J.F. Ruiz-Hidalgo; J.L. Lupiáñez; M. Picado; I. Segovia; I. Real and F. Ruiz, University of Granada.

- I. Gómez-Chacón; M. Castrillón and M. Gaspar, from the University Complutense of Madrid.

- M. Sierra and M.C. López, from University of Salamanca.

- B. Gómez, L. Puig and O. Monzó, University of Valencia.

The main objective of this work was to present the joint activity on mathematics and mathematics education, thought and written in Spanish, conducted by Spanish and American in more than 500 years of history and shared culture. We will stress the links established between Americans and Spaniards, as demonstrated by the information presented. We will underscore the scientific, technological, or cultural value of these events, their subsequent implications, and the social impact they produced in their time. 
As there is a common language, a shared history and culture, there are ways of thinking and doing math based on that language, that culture and that history. This work aims show and claim the shared heritage in mathematics and mathematics education in this community. We have done a selection of the information presented in the posters and we will comment it here.

We have organized the posters considering five general comprehensive periods:

1. Discovery and colonization.

2. The Creole society.

3. The Century of Independence.

4. 20th Century: mutual assistance and help.

5. Current cooperation.

Summary of key moments and ideas of the above mentioned periods.

1. Mathematics and Science in the Discovery of America.

On October 12, 1492, a Spanish expedition commanded by Admiral Christopher Columbus arrived at the island of Guanahani and took possession of the land in the name of their Majesties Isabella of Castile and Ferdinand of Aragon. This act of Discovery is essential to the birth of historical modernity and of science. It marks the origin of a sociocultural community, the Ibero-American community, based on the unique relationship between Spaniards and Americans. Columbus's goal was to reach Asia, that say, the island of Cipangu (Japan), which was thought to be at the same latitude as the Canary Islands. Columbus was not trying to discover a new continent, but rather to "reach the East by sailing West." The information that Columbus used involved several significant errors and to understand them it was needed a big change of ideas. Toscanelli's map, reflects the ideas of many navigators and geographers of the period, describes the route that Columbus believed he had travelled. He thus believed that the distance from the Canary Islands to Japan was 800 leagues by west $(4,500 \mathrm{~km})$, when it was actually about 3,500 leagues $(19,500 \mathrm{~km})$. These data were sufficient grounds for undertaking his first and the subsequent voyages. When Columbus arrives in the Antilles, he was convinced that he has reached the western coast of Asia hence his naming these lands the West Indies (Fig. 1).

Institutions: the first Universities. Starting with their first years in the colonies, the Crown, the Church, and the religious orders intervene in the area of education to teach and train clergy, government officials, and the middle classes. Their knowledge was classified into study in the trivium (grammar, rhetoric, and logic) and the quadrivium (arithmetic, geometry, music, and astronomy). Founding the Universities and Colleges in America is a historical feat and cultural phenomenon of prime importance, particularly in the first half of the 16th century. The first universities were the universities of Santo Domingo, Lima and Mexico, that were respectively founded in 1538 (Santo Domingo) and in 1551 (Lima and Mexico). 


\section{MATHEMATICS AND SCIENCE IN THE DISCOVERY OF AMERICA}

- Authors:

- Dr. Luis Rico. University of Granada. Irico@ugr.es Spanish ICMI Representative (CEMat)

- D.. Elena Castro- Rodríguez, University of Granada. elecr@correo.ugr.es

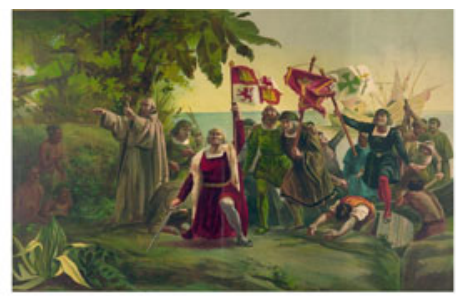

Columbus's goal was to reach the island of Cipangu (Japan), which was thought to be at the same latitude as the Canary Islands. Columbus was not trying to discover a new continent but rather to "reach the East by sailing west." Toscanelli's map, which reflects the ideas of many navigators and geographers of the period, describes the route that Columbus believed he had travelled.

The information that Columbus used involved several significant errors.

It assumed that the earth had a maximum circumference of $29,000 \mathrm{~km}$., estimated according to Posidonius and the length of a terrestrial degree, which was based on Arabic, not the shorter Italian, mile. Posidonius calculated the earth's circumference as less than three fourths of its real size, and this figure had been accepted as scientific truth since the time of Eratosthenes.

On October 12, 1492, a Spanish expedition commanded by Admiral Christopher Columbus arrived at the island of Guanahani and took possession of the land in the name of their Majesties Isabella of Castile and Ferdinand of Aragon. This act of Discovery is essential to the birth of historical modernity and of science. It marks the unique relationship between Spaniards and Americans.

On the other hand, interpreting the information from the voyages of Marco Polo, Columbus estimated the width of Eurasia to be 2250, subtracting only 1350 of ocean.

He thus believed that the distance from the Canary Islands to Japan was 800 leagues by west $(4500 \mathrm{~km})$, when it was actually about 3500 leagues (19,500 kilometers). But these data were sufficient grounds for undertaking his first and the subsequent voyages. When Columbus arrives in the Antilles, he is convinced that he has reached the western coast of Asia hence his naming these lands the West Indies.

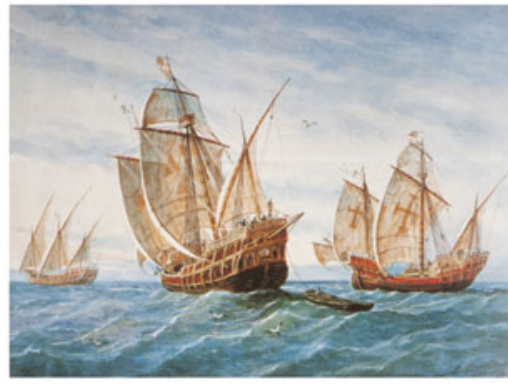

The problem of geographical longitudes also had to be solved to respond to the need for nautical maps. The demand for greater precision led to the emergence of new techniques and instruments for measurement, which required a considerable advance in scients particularly mathematics.
Columbus's subsequent voyages demonstrated the crucial importance of the new lands and cultures discovered for the construction and grounding of new knowledge. The exploration of the New World established a contrast between reality and speculative ancient doctrines on the size and shape of the earth's geography. This stimulated the spirit of free investigation and empirical contrast of hypotheses. Geography, cartography, cosmography, navigation, geodesy, and the physics of the globe ceased to be practical techniques and began their careers as physicalmathematical sciences.

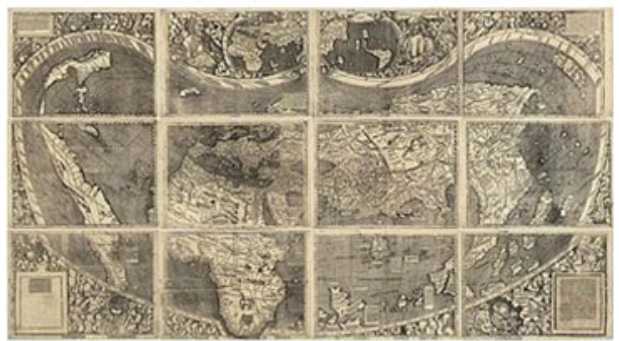

Although Columbus made four voyages, explored the islands of Guadalupe and Puerto Rico, reached the mouth of the Orinoco River, navigated the islands of Chacachacare and Margarita, Tobago and Granada, and landed in region of Panama, he died without knowing that he had discovered the "New World" for Europeans. In 1507, the German cartographer Waldseemüller published a geography book that included a map. The book represented the new lands and included the tales of a Florentine navigator, Amerigo Vespucci, who stated that the discoveries were not Asian lands, but a new continent. In Vespucci's honor, the 1507 map called the new lands America.

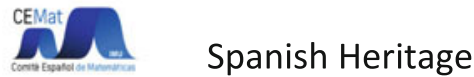

ICME12 SEOUL

Fig. 1 Mathematics and science in the discovery of America 


\section{The Creole Society.}

To talk about the Creole society we have fixed our attention in the following ideas:

- Scientific Policy of the First Bourbons. The Jesuits and Mathematics.

- Enlightenment Mathematics. The Reforms of Charles III.

- José Celestino Mutis. An Enlightened Scientist in the New World.

- Jorge Juan and Antonio de Ulloa. Meridian measurement in Quito.

At the beginning of the 18th century, the Jesuits assumed responsibility for educating the nobility, through Seminaries for Nobility, which began in Madrid. This institution's model of teaching spreads to Barcelona, Valencia, Gerona, and other cities. Based on its model, new centers are founded throughout the 18th century. In Mexico, the Royal Academy of San Carlos of the Noble Arts of New Spain is founded. These centers also trained the American elites. The Seminaries of Nobility become one of the most important centers of teaching and research in America. The Jesuits authored fertile textbooks in mathematics.

José Celestino Mutis y Bosio (Cadiz 1732; Bogotá 1808) Botanist, doctor, astronomer, and mathematician. Mutis developed important scientific work on American soil. He gave the inaugural speech for the Chair of Mathematics at the College of Our Lady of the Rosary in Santa Fe de Bogotá. There, he held the positions of rector and director. He determined the coordinates of Santa Fe de Bogotá, observed an eclipse of a satellite of Jupiter, and was one of the observers of the Transit of Venus on June, 1769.

Jorge Juan y Antonio de Ulloa. They participated in the expedition from 1735 to 1744 to measure an arc of $1^{\circ}$ of latitude near the equator and one near the pole, to determine the lemon or orange shape of the earth.

The Royal Academy of Sciences decided to undertake the task of obtaining precise data from two meridian positions at two locations on Earth: Lapland (North Pole) and the Viceroyalty of Peru (the equator). To do this, two expeditions were organized. If the measurements obtained by both expeditions were the same, the Earth was sphere-shaped. If the measurement was greater at the pole, there was flattening at the poles.

If the polar measurement was smaller, the French were right and the lemon shape shall be the model. To carry out the expedition to the cities of Quito and Cuenca, located today in the Republic of Ecuador (Fig. 2).

3. The Century of independence. We have fixed our attention on the following subjects.

- Educational Reforms in Hispano-America, based on the 1812 Constitution.

- The Compendium of Pure and Mixed Mathematics by D. José Mariano Vallejo.

- 19th-Century Mathematics.

- The Metric System in Textbooks in the Second Half of the 19th Century.

- The Mathematicians of Scientific '98. 


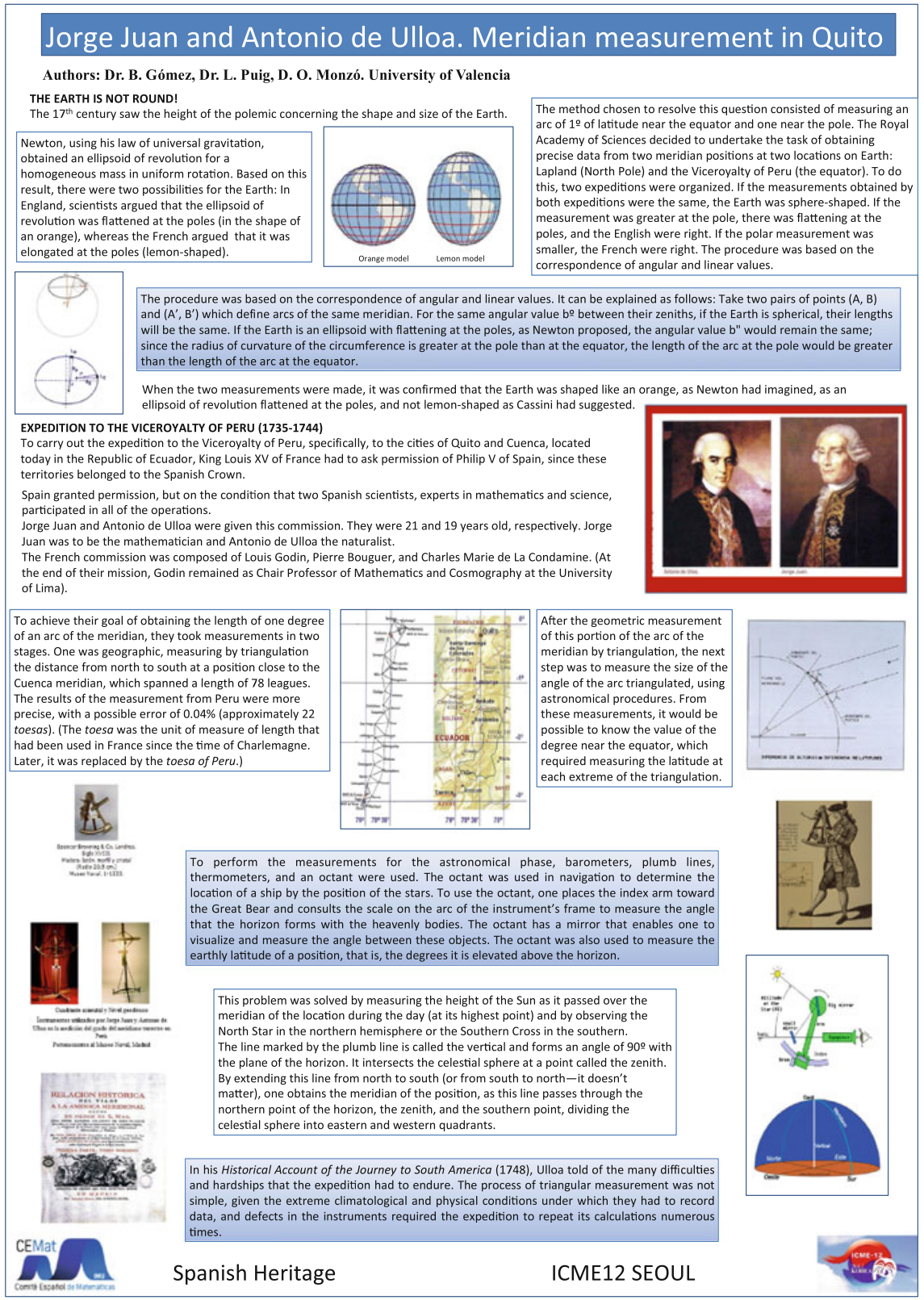

Fig. 2 Jorge Juan and Antonio de Ulloa. Meridian measurement in Quito 
Conception of education. Spanish resistance to Napoleon's invasion in 1808 led to the formation of the Courts of Cadiz, which developed the Constitution of 1812, oriented ideologically to exalt and safeguard individual liberty.

The Constitution's ninth title, dedicated to education, articulated the liberal idea of education, defending the idea of general, uniform education for all citizens and the need to form a Council for Public Education. This Council prepared a report that can be considered the most representative document on liberal ideology in matters of education. The report was published in Cadiz on September 9, 1813, under the following title: Report of the Council created by the Regency to propose the means for proceeding to regulate the various branches of Public Education.

It was established that "education must be universal, uniform, public, and free, and it must enjoy liberty." This Report formed the basis and origin of the educational reforms put into effect throughout Hispano-America after the revolutions that led to the independence of the Spanish colonies.

The 19th century is a turbulent period in the history of Spain. It begins with the invasions of Napoleon's armies in 1808 and ends with the Spanish-American War in 1898, known as the disaster of ' 98 . The beginning of the 19th century brings the independence of the former colonies in America, giving rise to the new American republics. Spain loses its status as world power. The 19th century ends with the loss of Cuba, Puerto Rico, and the Philippines and the defeat of the Spanish fleet in Santiago, Cuba. Spain concludes its political presence in America. Spain is aware of its cultural and educational decline, a feeling aggravated by the loss of its colonies. It is thought that the military defeat was caused in good part by the country's scientific and technical backwardness: the crisis of '98 (Fig. 3).

4. 20th Century: mutual assistance and help.

Where we are? Who are the leaders? We choose five points to reflect about our common work during the 20th Century.

- Andrés Manjón and the Ave María Schools at the end of the 19th Century.

- The Spanish Republican Exile: the Mathematicians in America.

- Researching Together: Return Journeys.

- The Iberoamerican Mathematical Olympiad.

- ICME 8 Seville (Spain), July 1996. Current research and cooperation (Fig. 4).

5. Current cooperation.

To describe this point we selected the following reflections:

- Research Centers.

- Journals, research and collaboration in Mathematics Education.

- Miguel de Guzmán Ozámiz (1936-2004) Academic, scientific, and educational legacy.

- Mathematical Research in Ibero-America, Spain and Portugal.

- Spanish Mathematics: the last 20 years (Fig. 5). 


\title{
19TH-CENTURY MATHEMATICS
}

Author: Javier Peralta. Faculty of Teacher Training and Education.

Autonomous University of Madrid

\begin{abstract}
After the death of Ferdinand VII (1836), the governments of Isabel II entered a favorable period for Spanish education and science, which had lagged behind the times. Educational reforms were carried out and new education and science, which had lagged behind the times. Educational reforms were carried out and new institutions founded. This process gained momentum during what is known as the six democratic years (1868-1874), when the queen was dethroned by the Revolutionary Councils, with their democratic ideology (freedom of religion, universal suffrage...).

In 1876, the Institute of Free Teaching was created. This institution played a highly beneficial role in education, and the reform movement for renewal received new stimuli with the Crisis of ' 98 .

This cultural and scientific renaissance would have a positive influence on the development of Spanish mathematics. It would also have repercussions for education in Cuba and Puerto Rico.
\end{abstract}

First reforms and institutions

\section{5: The Pidal Plan}

Establishes the Bachelor of Science (within the Faculty of Philosophy)

Creates provincial Institutions for Secondary Education.

\section{7: Moyano Law}

First law on education in Spain: creates the Faculty of Sciences (Madrid).

1858: Degree of Bachelor of Exact Sciences created.

Paraninfo de la Universidad de Madrid (1852)

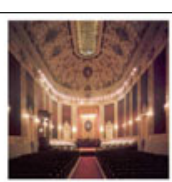

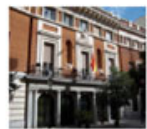

1847 Creation of the Royal Academy

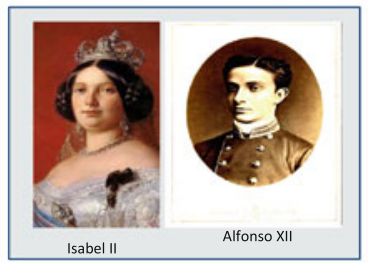

sabel II

Development of mathematics

Introduction of new theories (last third of the century)

S. Archilla, L. Clariana: Cauchy analysis.

J. Echegaray: Chasles geometry, calculus of variations, determinants, t the Galois Theory, elliptic and Abelian functions.

V. Reyes: Non-Euclidean geometries, symbolic logic.

Scientific journals (founded in the mid-19th century) Mathematics and Physics Monthly (Cadiz, 1848). . Journal of Advances in the Exact, Physical, and Natural Sciences (Madrid, 1950).

Journal of the Society of Teachers of Science (Madrid, 1874)

Science Chronicle (Barcelona, 1878)

Progress in Mathematics (Zaragoza, 1891)

Archive of Pure and Applied Mathematics (Valencia, 1896).

The Aspirant (Toledo, 1897).

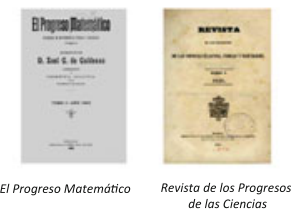

de las Ciencias

Activity in Cuba and Puerto Rico prior to 1998

Many Cubans and Puerto Ricans finished their education in the US, although some did so on the Spanish Peninsula. Some returned to work in their birthplaces, but others remained on the Peninsula.

Born in Puerto Rico. Stud physical-mathematic sciences physical-mathematic sciences in Puerto Rico Abolitionors. Members of Parliament:

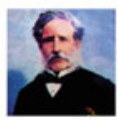

José Julián Acosta (1825-1891 Chair of Agriculture and Director of the Institute of San Juan, Puerto Rico.
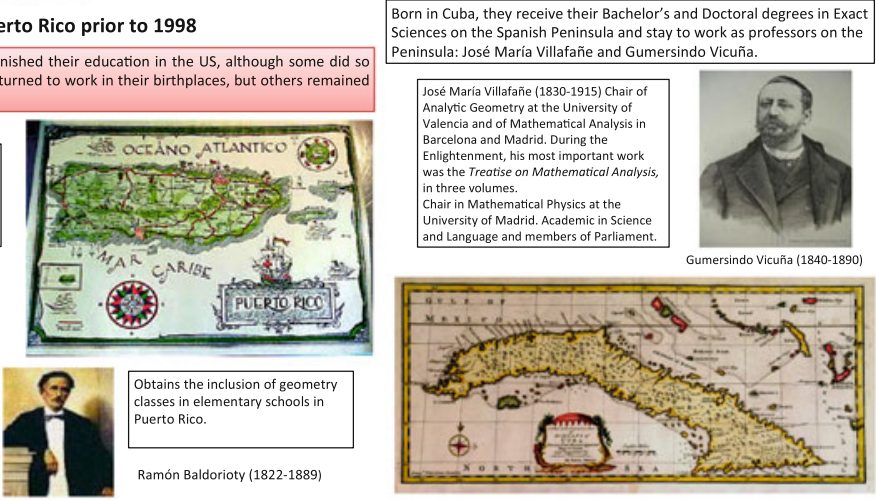

First half of the century: Education is in the hands of religious orders and the Economic Societies of the Friends of the Nation. Around the 1940s, special laws are enacted for the islands that adapt education to the Spanish regulations and impose greater control by the State.

enacted for the islands that adapt education to the Spanish regulations and impose greater control by the State.
-1844: publication of the General plan for public education for the islands of Cuba and Puerto Rico, which remains in effect from 1863 and 1865 , respectively. From this time onward, the Pidal Plan is applied, but under the strict authority of the governor

- Normal Schools are created: one in Cuba in 1857 (until 1864) and two more in 1890; and one in Puerto Rico in 1882.

- Institutions of Secondary Education are created: one in Cuba in 1863 (Cuba would ultimately have four); and one in Puerto Rico in 1882.

University: Cuba has a university from 1728 onward. The Royal and Papal University of San Geronimo was founded by Dominicans. In the $19^{\text {th }}$ century, this university was gradually adapted to the Spanish legislation. In 1842, it was secularized and took the name of the Royal and Literary University of Havana, which underwent successive reforms and whose study programs were assimilated into those on the Peninsula.

Puerto Rico: The Athenaeum was created in 1863, with authorization to impart higher education under the supervision of the Cuban university system. Shortly after, the University District is established in Havana, for the system of public education on both islands.

\section{Spanish Heritage}

ICME12 SEOUL

Fig. 3 19th-century mathematics 


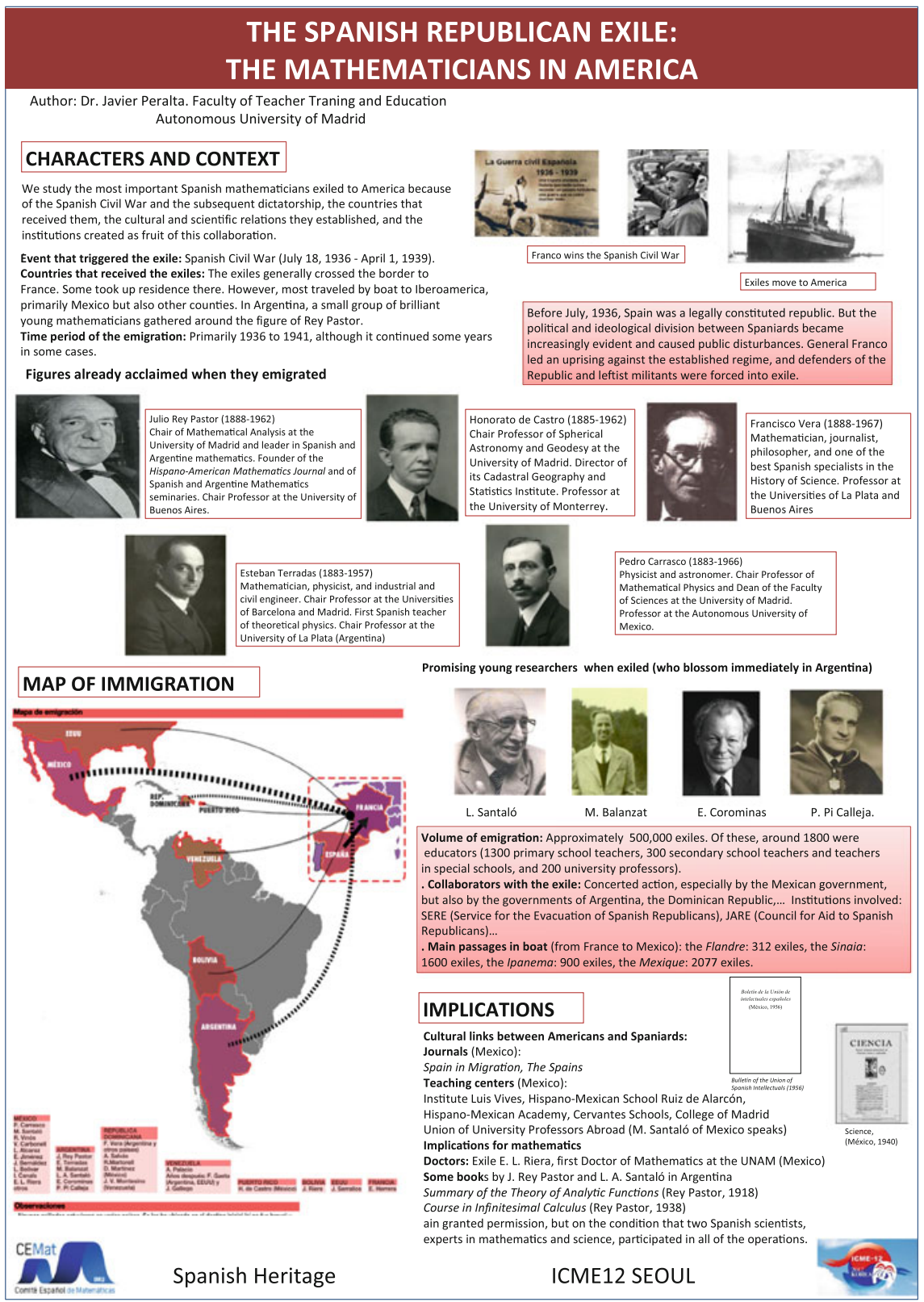

Fig. 4 The Spanish Republican exile: the mathematician in America 


\section{JOURNALS, RESEARCH AND COLLABORATION IN MATHEMATICS EDUCATION}

Alexander Maz-Machado, Noelia Jiménez-Fanjul University of Córdoba (Spain)

Iberoamerican countries have a wide variety of journals for both research and popularization of Mathematics Education where Spanish, Portuguese, and Iberoamerican researchers currently publish.

To collect and disseminate bibliographic Information about scientific publications produced in Iberoamerican countries was created a network of bibliographical institutions that work collaboratively: LATINDEX is the product of this cooperation,

Two Iberoamerican journals in the area are indexed in the JCR: the Bolema-Mathematics Education Bulletin-Boletim de Educacao Matematica (BOLEMA) and the Journal of Latin American Research on Mathematics EducationRevista Latinoamericana de Investigación en Matemática Educativa-Relime (RELIME).

International collaboration was strengthened in 2005, with the creation of the Iberoamerican Federation of Societies for Mathematics Education. Members include Societies from Argentina, Brazil, Chile, Columbia, Spain, Peru, Portugal, and Uruguay. This Society publishes the journal Unión.

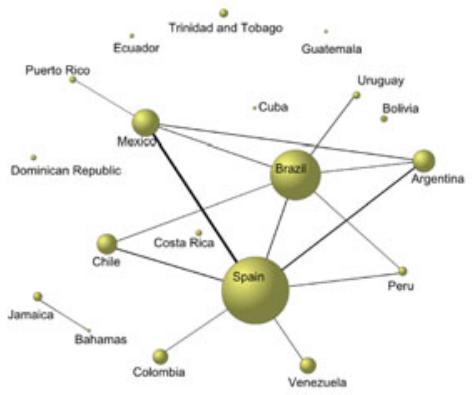

Red de colaboración en artículos de Educación Matemática indexados en SCOPUS

If we examine the scientific productivity in the 770 articles indexed in SCOPUS as authored by Spanish or Iberoamerican researchers, we find systematic collaboration. This collaboration generates a network that revolves around Spain, Brazil, and Mexico.

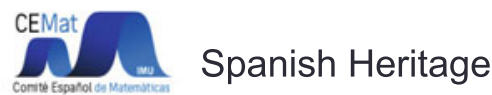

\section{Doctoral Programs \\ In training researchers in Spanish-speaking countries, the CINVESTAV of Mexico, the University of Granada, and the Autonomous University of Barcelona are leading in number and quality of PhDs conducted.}

International Congresses
A site for meeting and collaboration between
Spain and Iberoamerica. Among the most
significant are: the Latin American Meetings for
Educational Mathematics ([RELME]), the Inter
American Conference of Mathematics
Education [CIAEM]), the Iberoamerican
Congress of Mathematics Education [CIBEM])
and, in Spain, the Symposium for the Spanish
Society for Mathematics Education (Simposio
de la Sociedad Española de Educación
Matemática [SEIEM])

ICME12 SEOUL

Fig. 5 Journals, research and collaboration in mathematic education 
The goal of the presentation was to show and underline the relevance of the cultural and scientific cooperation in mathematics and mathematics education between Spain and the American Republics over the last 500 years. The presentation seeks to publicize this common mathematical heritage by emphasizing its importance and the far-reaching influence these relationships have had and continue to have for science, technology, and education in our countries.

Open Access This chapter is distributed under the terms of the Creative Commons Attribution Noncommercial License, which permits any noncommercial use, distribution, and reproduction in any medium, provided the original author(s) and source are credited. 